\section{Some things on my mind}

There are some things that just get my goat, so to speak. One of these is the poaching that I see in parking spaces reserved for the handicapped. We can quibble about that term "handicapped" at some other time. What is more germane, I think, is the lack of respect for these shown by a certain segment of the population. When confronted with the fact of their transgression, many offenders offer the following: "I was just going to be there a little while," or "I didn't even notice it was reserved," or "there were a couple and nobody was in one." A young woman I know, who legitimately uses a handicapped sticker, tried to park at a place of business only to find a car, with its emergency lights blinking, parked in the only spot available. Out of the store sauntered a young man over to the car. My friend blocked his exit with her car and asked, "Where is the emergency?" The reply, of course, was "I was only there a little while."

Some culprits get very defensive or aggressive when their error is pointed out. The general assumption seems to be that "I am more important" than the people for whom this provision was made. What is even more surprising to me is the fact that some of these things are done by people who, under most circumstances, would show a lot more respect for the rights of others. Getting a desirable parking spot is always nice but must we cheat? There are even instances of able-bodied people either illegally seeking to obtain a handicapped permit or borrowing someone else's or even stealing the sticker from one who legitimately needs it, all for convenience. Whatever happened to fair play, much less the observance of the law? There are other abuses related to these areas. How many times have we seen people push shopping carts into these areas at the supermarket or other stores, rather than into the areas designed for that purpose? In what must be an even greater display of empty-headedness, a real "no-brainer," snow removal people push snowbanks into or so close to handicapped parking as to make the spaces unsafe and unusable. Some wheelchair users tell me that handicapped spaces are often too narrow to allow for needed dooropening space if another car is parked alongside. Another complaint, one fairly obvious at times, is that the handicapped reserved spaces are located in the wrong places to be really most beneficial.

While we are on this subject, let's talk about some allied problems. Have you ever held a door open for someone with a disability only to have some clod almost run that person over getting through the door ahead of them? Makes you wonder. Just a word about this act of courtesy: Don't start holding a door open too far in advance for someone. It makes that person feel he or she has to rush, and perhaps that isn't possible. Save the person a little embarrassment and watch your timing. If the person you want to help waves you off, he or she generally means "thanks but I can do it myself." A smile and an OK lets everyone know that no harm is done.

Our society has made some progress with regard to physical accommodations, but we still see ramps which are too steep, steps with no handrails, automatic doors that snap shut like traps, and bathroom facilities located at great distances from the center of activity, some designed so poorly as to be useless to wheelchair users.

More distressing to me, however, is the lack of progress we have made in other areas, especially in changing people's outlook. There is no health care crisis, some maintain. Perhaps I may define "crisis" differently. But were I a person with a disability, who has incurred catastrophic debt because I could not get health insurance, then I think "crisis" is a very appropriate word indeed. This nation needs to address the issue of lack of available coverage and needs to address it now. Only about half of the people ages 15-64 with severe disabilities have private health insurance, compared with $80 \%$ of those without disabilities. The severely disabled may be denied insurance on the grounds of pre-existing conditions or simply because they cannot afford to purchase it, since approximately only $22 \%$ of the 16 -64-year-olds with severe disabilities are employed (US Census Bureau, 1991-1992). These might not be the best-paying jobs to begin with, plus the fact that a condition "pre-exists." So what do you do besides spend all your assets to pay for care? The solution, of course, is to be wealthy. Nice work if you can get it. To my mind, there is a crisis, and this issue requires redress. If this makes me a member of the much-maligned "special interest groups," so be it. Isn't that what our organizations are all about?

-Henry L. Kanar, DDS, MS Associate Professor of Dentistry University of Michigan Ann Arbor 